\title{
Bone Remodeling, Biomaterials and Technological Applications: Revisiting Basic Concepts
}

\author{
Patrícia C. Salgado ${ }^{1}$, Plínio C. Sathler ${ }^{2,3}$, Helena C. Castro ${ }^{2,3}$, Gutemberg G. Alves ${ }^{2}$, \\ Aline M. de Oliveira ${ }^{4}$, Rodrigo C. de Oliveira ${ }^{5}$, Mônica D. C. Maia ${ }^{6}$, Carlos R. Rodrigues ${ }^{7}$, \\ Paulo G. Coelho ${ }^{8}$, Andre Fuly², Lúcio M. Cabral' ${ }^{2}$ Jose M. Granjeiro ${ }^{2}$
}

\begin{abstract}
${ }^{1}$ Program of Post-Graduation in Medical Sciences, Fluminense Federal University, Niterói, Brazil; ${ }^{2}$ Post-Graduation in Biology of Interactions, Institute of Biology, Fluminense Federal University, Niterói, Brazil; ${ }^{3}$ Program of Post-Graduation in Pathology, Fluminense Federal University, Niterói, Brazil; ${ }^{4}$ Clinical Research Unit, Antonio Pedro Hospital, Nucleus of Cell Therapy, Fluminense Federal University, Niterói, Brazil; ${ }^{5}$ School of Odontology, Fluminense Federal University, Niterói, Brazil; ${ }^{6}$ Department of Biological Sciences, Dental School of Bauru, São Paulo University, São Paulo, Brazil; ${ }^{7}$ School of Pharmacy, Federal University of Rio de Janeiro, Rio de Janeiro, Brazil; ${ }^{8}$ Department of Biomaterials and Biomimetics, New York University, New York, USA. Email: jmgranjeiro@vm.uff.br, hcastrorangel@yahoo.com.br
\end{abstract}

Received March 24 $4^{\text {th }}, 2011$; revised April 29 2011 ; accepted May $8^{\text {th }}, 2011$.

\begin{abstract}
Presently, several different graft materials are employed in regenerative or corrective bone surgery. However current misconceptions about these biomaterials, their use and risks may compromise their correct application and development. To unveil these misconceptions, this work briefly reviewed concepts about bone remodeling, grafts classification and manufacturing processes, with a special focus on calcium phosphate materials as an example of a current employed biomaterial. Thus a search on the last decade was performed in Medline, LILACS, Scielo and other scientific electronic libraries using as keywords biomaterials, bone remodeling, regeneration, biocompatible materials, hydroxyapatite and therapeutic risks. Our search showed not only an accelerated biotechnological development that brought significant advances to biomaterials use on bone remodeling treatments but also several therapeutic risks that should not be ignored. The biomaterials specificity and limitations to clinical application point to the current need for developing safer products with better interactions with the biological microenvironments.
\end{abstract}

Keywords: Biocompatible Materials, Bone Remodeling, Hydroxyapatite, Therapeutic Risks

\section{Introduction}

In the last ten years, hundreds of thousands of individuals were affected by deficiencies resulting from trauma, aging, degenerations and other pathologies involving the musculoskeletal system. Thus the last decade (2000-2010) was declared by The World Health Organization as the Bone and Joint Decade [1].

As a result of the musculoskeletal-related disease high incidence, the costs and incomes with treatments and medical support to take caring and maintain the quality of life of these individuals had significantly increased. This reinforced the need for novel technologies and methods to provide more feasible and efficient therapeutic options such as the biomaterials.

In this work, we briefly reviewed several topics related to Biomaterials that are promising therapeutic alternatives in bone defect treatment. This review approached different concepts such as bone repair, graft classification and manufacturing technologies, also including their applications, advantages and risks. We also provided a more detailed description of the main characteristics and issues related to calcium phosphate-based biomaterials. This alloplastic materials group is of wide application and is shown as an example of interesting results and first-hand experience.

\subsection{Biomaterials: A Brief Beginning}

The term biomaterials, also referred as biomedical materials, includes any substance (other than drugs) or combination of substances, synthetic or natural in origin, which can be used for any period of time, as a whole or as a part of a system, which treats, improves, or replaces any tissue, organ, or function of the body $[2,3]$. Areas such as odontology adopted testing procedures and improved these new biomaterials also allowing fast devel- 
opment and application processes. In this practice area, the use of biomaterials go as far as bone grafting in regenerative or corrective bone surgeries and in procedures for restoring bone tissue lost during periodontal disease or endodontic lesions [4,5], filling the alveolar of extracted teeth to prevent alveolar ridge volume reduction [6] and lifting maxillary sinus floor and atrophic alveolar ridge reconstructions [7-9], among others [10].

Currently, biomaterials are subjected to specific standards for testing and evaluation [11,12]. According to those, any material intended for clinical use must present significant biocompatibility defined as "the ability of a material to perform with an appropriate host response in a specific application, without eliciting any undesirable local or systemic effects in the recipient or beneficiary of that therapy, but generating the most appropriate beneficial cellular or tissue response in that specific situation" $[13,14]$. Therefore, the biomechanical properties of a biomaterial must be adequate and tolerated by the host tissue [15].

In order to present such desirable features, the biomaterials are produced associated to several materials and substances [16]. For example, the use of bone grafts together with growth factors such as PDGF, TGF- $\alpha$ and bone morphogenetic proteins (BMPs) is based on the association of natural or recombinant proteins to a carrier such as biological or synthetic polymers (collagen or poly-L-lactic acid, respectively), ceramics (hydr-oxyapatite, inorganic bovine bone) and other materials [17].

A great variety of biomaterials is described in literature for bone bioengineering purposes in cell therapy [18]. In these cases, the carrier must present (Figure 1):

1) adaptability to the damaged area;

2) osteoconductivity, characterized by good adhesion, proliferation and maturation of osteoprogenitor cells;

3) ability of acting as a barrier to surrounding tissues;

4) time of resorption compatible to the requirements for bone formation, without interfering with the substitution of the material by neoformed bone;

5) biocompatibility, non-immunogenicity and atoxicity;

6) radioluscence, allowing the radiographic distinction of graft from newly formed bone;

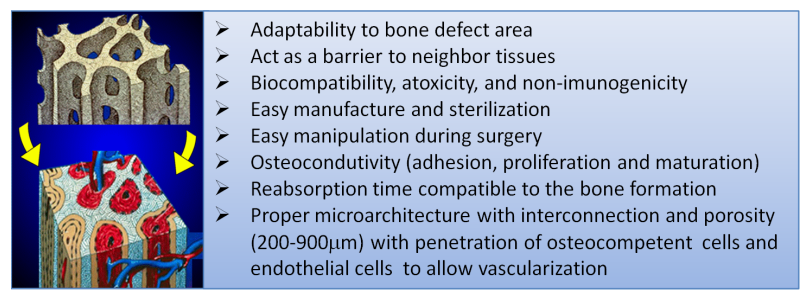

Figure 1. Requirements for biomaterials act as substitute in bone bioengineering and cell therapy.
7) easy manufacture and sterilization;

8) easy handling during surgery, avoiding complex preoperatory procedures which increase the risk of infection and

9) adequate microarchitecture, including interconnections and porosities $(200-900 \mu \mathrm{m})$, allowing the penetration of osteocompetent and endothelial cells and the vascularization of the neoformed tissue [18,19].

Several protocols for new biomaterials production and testing have been described in the last few years, and some are used regularly in areas such as Odontology and Orthopedics. However, to understand the principles and functioning of these biomaterials and their protocols, first it is necessary to take a look into the targets and biological systems affected by them.

\subsection{Tissue and Bone Repair: Knowing the Target}

Bone represents a specialized conjunctive tissue, characterized by the mineralization of the extracellular matrix (bone matrix), which can be composed of intramembranous or endochondral ossifications [20]. Intramembranous ossification occurs in the inner portions of the conjunctive membrane, where mesenchymal cells differentiate in osteoblasts starting bones formation (i.e. mandible body, frontal, parietal, temporal, maxillary and parts of the occipital). Differently, in endochondral ossifications bone is formed over a cartilaginous frame, which is gradually substituted by bone tissue [21].

At the molecular level, bone is constituted by an organic portion, representing $35 \%$ of the bone matrix composed mostly by type I collagen fibers (95\%), together with proteoglycans, glycoproteins and growth factors [22]. The remaining inorganic components correspond to $65 \%$ of bone weight and include calcium phosphate crystals with apatite structure. Those crystals are deposited along the collagen fibers and are responsible for the toughness and resistance of bone tissue [23].

Bone tissue usually presents a remarkable capacity of repair and regenerated tissue is very similar to the originnal bone. This is in contrast to other tissues that present the formation of fibrous connective tissue during repair (i.e. muscle and tendons) [24].

However, there are some conditions in which bone tissue is unable to regenerate correctly. Bone tissue development and repair are extremely dependent on extracellular matrix remodeling and local angiogenesis. Therefore several bone diseases result from the unbalance of those processes $[21,25,26]$. In the last decades, some studies have focused on the role and regulation of bone remodeling through apposition and resorption [27]. One of their main purposes was to identify signaling proteins and their role in such processes [21,25,28]. 
Literature described the bone remodeling dependence on growth factors, cytokines, BMPs, matrix metalloproteinases (MMPs), alkaline phosphatase, tartrate-resistant acid phosphatase (TRAP) and nitric oxide (NO) [29], which regulate apposition and resorption in a structured way. Bone repair also depends on an adequate blood supply, mechanical stability cell migration, matrix deposition and remodeling, among other processes [21,30-32] (Figure 2).

The use of biomaterials as promoters of bone repair may lead to: 1) formation of a surrounding fibrous connective tissue, known as repair by cicatrization that is an undesired process, or 2) material absorption and close integration to the tissue, known as repair by regeneration that is desirable to clinical use [33-35].

The regenerative bone repair processes become more predictable with the Guided Tissue Regeneration (GTR) technique. It is characterized by a physical barrier that is placed around to the damaged area or to the biomaterial, to promote bone cells proliferation and exclude undesirable cells. The bone cells proliferation is responsible for the regeneration of the damaged or lost tissue [36-39] (Figure 2).

\subsection{Biomaterials and Blood: Feeding the System}

The survival of osteocytes in grafted bone is directly related not only to blood vessels support but also to viable surfaces of both endosteum and periosteum. Usually, grafts originated from bone marrow present a higher probability of helping cell survival by improving nutrient diffusion and promoting revascularization [17].

Besides nutrient and oxygen supply, the coagulation is another important aspect of the close relation between biomaterials and blood. Although many osteoconductive and degradable biomaterials are available, some interfere with platelet function or the coagulation cascade. Therefore the risk of thrombus formation during, and after prosthetic surgery increases for the patient [40].

Sometimes postoperative deep vein thrombosis occurs due to the biomaterial release into circulation (i.e. Bone Cement Implantation Syndrome - BCIS) [41-43]. In other cases, soluble components on bone cements are considered toxic (i.e. methacrylate monomers) $[40,44]$.

The contact between blood and a specific biomaterial may lead to several other coagulopathies and vascular disorders, as well as pulmonary, renal and neuronal dysfunctions [45]. Usually, these disorders are associated with mild to strong inflammatory reactions. Indeed, the activation of blood plasma cascade systems (coagulation, complement and kallikrein systems) occurs right after blood contact with the biomaterial with subsequent adsorption of plasma proteins, depending on the biomaterial structural and chemical features $[46,47]$.

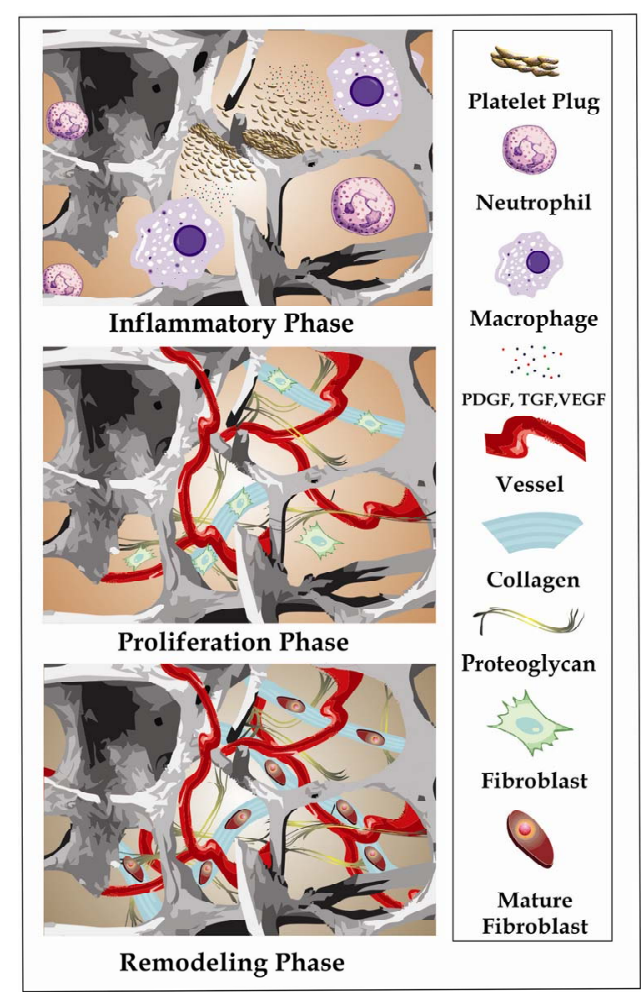

Figure 2. Stages of process bone tissue repair. Inflammatory, proliferative and remodeling phases.

Usually the inflammatory response to biomaterials starts with the activation of the complement system and $\mathrm{C} 3 \mathrm{~b}$ deposition on the biomaterial surface. The sub-sequent generation of C3a and C5a triggers leukocyte release of cytokines, prostaglandins and leukotrienes, with a wide range of pharmacological effects on cells $[48,49]$ (Figure 3).

The activation of complement also induces platelet aggregation as well as the coagulation system. Even tough these mechanisms are not fully understood, the participation of the intrinsic and extrinsic pathways as a whole has been reported [48,50,51].

Therefore, safety evaluation is almost as important as the development of new biomaterials for any area of use. This should be prior and during the biomaterial application and obviously includes studies involving the biomaterials interaction with all blood systems.

\subsection{How and Why Classify Biomaterials?}

Biomaterials may be classified based on different biological features including postgrafting action and origin. These features are important to the procedures and the required attention as well as the further studies for fully understand of the biomaterial effects (Table 1).

\subsection{Postgrafting Action}

Bone grafts can be classified as osteogeneic, osteoinduc- 


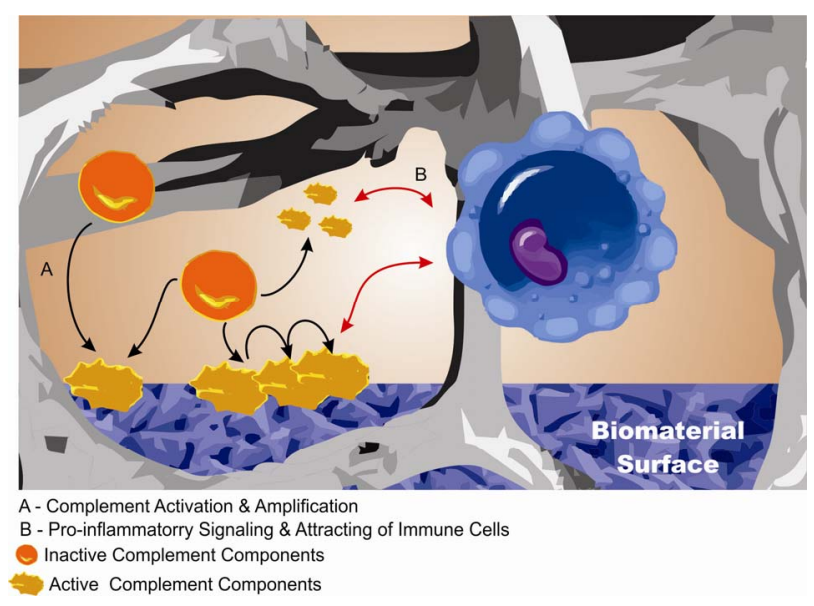

Figure 3. Complement system activation through binding to the biomaterial surface. The activated complement attracts immune cells and triggers inflammation.

Table 1. Comparison of biological characteristics of biomaterials based on their origin and biological profile.

\begin{tabular}{|c|c|c|}
\hline \multicolumn{2}{|c|}{ Classification } & \multirow{2}{*}{ Biological Characteristic } \\
\hline Based on & Type & \\
\hline \multirow{4}{*}{$\begin{array}{l}\text { Biological } \\
\text { profile }\end{array}$} & Osteogeneic & $\begin{array}{l}\text { Living bone cells are inserted onto a } \\
\text { receptor site and maintains the capacity } \\
\text { of generating novel bone tissue }\end{array}$ \\
\hline & Osteoinductive & $\begin{array}{l}\text { Mesenchymal stem cells of graft site } \\
\text { surroundings are induced to differentiate } \\
\text { into osteogeneic cell lineages }\end{array}$ \\
\hline & Osteoconductive & $\begin{array}{l}\text { able to orient the formation of new bone } \\
\text { tissue through its support matrix, acting } \\
\text { as a scaffold that can be simultaneously } \\
\text { absorbed and substituted by bone tissue }\end{array}$ \\
\hline & Osteopromotive & $\begin{array}{l}\text { Allows Guided Tissue Regeneration } \\
\text { (GTR) }\end{array}$ \\
\hline \multirow{4}{*}{ Origin } & Autogeneic & $\begin{array}{l}\text { obtained from unaffected donor sites } \\
\text { from the own receptor individual }\end{array}$ \\
\hline & Allogeneic & $\begin{array}{l}\text { obtained from the bone tissue of an } \\
\text { individual of the same species of the } \\
\text { receptor }\end{array}$ \\
\hline & Xenogeneic & $\begin{array}{l}\text { obtained from individuals of different } \\
\text { species from the donor }\end{array}$ \\
\hline & Alloplastic & $\begin{array}{l}\text { synthetic materials, manufactured in } \\
\text { different shapes, textures, sizes and } \\
\text { compositions }\end{array}$ \\
\hline
\end{tabular}

tive, osteoconductive and/or osteopromotive based on their biological effects after implantation onto a bone defect. Some materials may be classified into more than one functional class, thus requiring attention and further studies for fully understand of the biomaterial effects.

Osteogeneic: in osteogeneic grafts, living bone cells are inserted onto a receptor site and maintains the capacity of generating novel bone tissue. Autogeneic bone represents the main example of a graft material with osteogeneic properties, since it is able to form bone tissue even in the absence of undifferentiated mesenchymal cells. In fact, autogeneic graft materials are also able to induce osteoinduction, osteoconduction and osteopromotion [24], as described in the following sections.

Osteoinductive: This is a common classification for some graft materials in which mesenchymal stem cells of graft site surroundings are stimulated to differentiate into osteogeneic cell lineages. This mechanism is directly related to the activity of BMPs [52,53]. Osteoinductive grafts contribute significantly to the formation of new tissue during bone remodeling processes. This is mainly observed by using platelet-rich plasma, growth factors, demineralized lyophilized bone or frozen/irradiated autogeneic bone [54].

Osteoconductive: This biomaterial is able to orient the formation of new bone tissue through its support matrix, acting as a scaffold that can be simultaneously absorbed and substituted by bone tissue [55]. Osteoconductive biomaterials allow for bone apposition on their surfaces, guiding the repair from the border of the lesion to its center. Osteoconductive media do not promote osteoblast differentiation but ease inner bone growth and fibrovascular tissue formation on the graft area [56,57]. Cortical autogeneic bone, allogeneic mineralized tissue from bone banks and alloplastic or synthetic materials such as ceramics, polymers and composites are examples of osteoconductive materials.

Osteopromotive: The principle of osteopromotion is related to the Guided Tissue Regeneration (GTR) and the properties of physical membranes or barriers. Currently, two classes of barriers can be used for such purpose: a) absorbable (ex: polylactic acid, polyglycolic acid or type I and type III collagen) and b) non-absorbable membranes (ex: expanded-polytetrafluorethylene - e-PTFE). The barrier selection is directly linked to defect type, cost/benefit ratio and availability and/or interest of the patient in submitting to a second surgery for the removal of non-absorbable membranes [37,58,59].

Those barriers, when employed on GTR, should obey the following criteria:

1) biocompatibility;

2) permeability, allowing the diffusion of plasma and nutrients, but impending the transit of cells;

3) provide physical support to surrounding soft tissues, preventing them to collapse into the blood clot space;

4) protect blood vessels while the clot undergoes a reorganizing process;

5) exclude competitive cells;

6) prevent the formation of scars

7) present easy handling [37]. 


\subsection{Origin}

Another classification for biomaterials is based on their origin, which include autogeneic, allogeneic, xenogeneic or alloplastic. These classes are briefly described below with the advantages and disadvantages, including a more detailed description of allogeneic calcium phosphate materials [60].

Autogenous bone grafts: Also known as autografts, they are obtained from unaffected donor sites from the own receptor individual. The regeneration of the bone defect occurs by mechanisms involving osteogenesis, osteoinduction and osteoconduction $[17,46,61,62]$. These are the most used grafts due to their biocompatibility and non-immunogenicity, being considered sometimes as standards for bone-grafting [61]. In this graft type, the autogeneic bone matrix allows for the transference of living bone cells from the donor site to the receptor region.

Autogeneic grafts can be extracted from cortical bones, their medullary portions or a combination of both [17]. According to literature, bone-marrow grafts are most efficient due to their higher content of osteoprogenitor cells [63]. They can be obtained by both extraoral (iliac crest, tibia or skull) or intraoral areas (retromolar region, mandibular symphisys and maxillary tuberosities), depending on the volume and composition of the desired graft [10]. Once collected, the autogeneic material should be used immediately or stored in lactated Ringer medium or saline physiological solution to maintain cell viability.

In the other hand, autogeneic grafts present some disadvantages/risks, which for extraoral grafts, include: 1) patient hospitalization, 2) morbidity of the donor site, 3 ) post operatory scars and 4) discomfort during recovery. Differently, for intraoral grafts they are 1) higher patient's morbidity and 2) limited quantity and quality of material available for collecting $[16,23,61]$. These risks have stimulated the development of bone grafts from alternative biomaterials.

Allogenous bone grafts: They are obtained from the bone tissue of an individual of the same species of the receptor. The allogeneic grafts present osteoinduction and osteoconduction abilities, being processed in sterile conditions and stored in bone banks $[16,23,64]$. The advantages of allogeneic bone grafts are 1) no need of a donor site, 2) reduced use of anesthetics, 3) less bleedings, 4) unlimited amounts of graft material and 5) lower risks of surgical complications. Their main disadvantages include mostly 1) risk of transmission of infectious diseases, 2) host immune response and 3) lower predictability for the grafting outcome.

Allogeneic grafts can be commercialized in several different forms, reflecting on different production costs and efficacies including:

1) frozen grafts, known as the most antigenic form;

2) lyophilized grafts, produced by washing the cortical and medullary bone from the donor, followed by triturating, nitrogen freeze-drying, sterilization by ethylene oxide or irradiation and storage;

3) lyophilized and demineralized grafts, through a previous treatment with $0.6 \mathrm{M}$ nitric or chloridric acid and

4) irradiated grafts, which present some controversies by the lack of references on safety and efficacy of their osteoinductive properties [65].

Xenogenous bone grafts: They are also known as xenografts and are obtained from individuals of different species from the donor [66]. The most common grafts are collected from bovine bone, but literature also described porcine or caprine materials [23]. Their use presents similar advantages of allogeneic grafts, with predictable results when surgical rules are followed [67]. On the other hand, there are also disadvantages including: 1) the risk of interspecific transmission of infectious diseases, 1) host immune response and 3) lower acceptance by patients and professionals due to cultural and religious aspects of using animals material.

Alloplastic bone grafts: These are synthetic materials manufactured in different shapes, textures, sizes and compositions. This category includes metallic grafts and their alloys, calcium phosphate ceramics (hydroxyapatite and tricalcium phosphate), calcium carbonate, calcium sulphate, Hard Tissue Replacement (HTR) polymers and bioglass [68]. These materials can be classified based on their porosity (dense, microporous or macroporous), crystallinity (crystalline or amorphous) and solubility (absorbable or unabsorbable) [69,70].

Synthetic grafts are associated to an osteoconductive action, characterized by bone growth into the graft material matrix, which acts as a scaffold to the regeneration of lost bone tissue $[16,61,63,69]$.

Besides their biological properties, these materials also present relevant chemical (main composition, impurities and ionic reposition) and physical characteristics (shape, porosity, surface area and crystallinity), which directly affect material absorption function, velocity and range $[65,71]$.

Other characteristics such as morphology, roughness, wettability and surface energy of the employed biomaterial also affects cell adhesion, proliferation and differentiation, specially on osteoblasts, contributing to the formation of either fibrous or bone tissue $[65,72]$. Therefore, the manufacture of alloplastic materials for bone regeneration purposes must be submitted to accurate controls that verify the physical, chemical and mechanical properties of the material [73]. 


\subsection{Biomaterials Based on Calcium Phosphate}

Calcium phosphates have been used for a long time as alloplastic materials for bone grafts or as a cover for dental implants. They are known as bioactive materials, due to their capacity of actively participating on both cicatrization and regeneration of bone tissue [74]. This capacity results from the similarity between calcium phosphate materials and the apatites found on bone tissue $[23,63,69]$.

The major advantage of calcium phosphate-based graft materials is that both calcium and phosphate ions do not interfere on cell function and physiology of adjacent tissues. This feature grants a favorable tissue response to treatment with adequate toughness and mechanical resistance to compression. Furthermore, due to partial dissolution onto the physiological medium, these materials release phosphate and free calcium ions. These ions seem to act as catalysts for bone formation and precipitation of a carbonated apatite layer over the surface of the biomaterial, which allow the chemical bonding to the neoformed bone [57,63].

Calcium phosphates can be manufactured on microporous (dense) or macroporous forms. Microporous ceramics present maximum porosity of $5 \%$ per volume, with a maximum pore diameter of $1 \mu \mathrm{m}$. This results in highly dense materials, with elevated resistance to compression [70]. Macroporous calcium phosphates, on the other hand, present $100 \mu \mathrm{m}$ to $500 \mu \mathrm{m}$ diameter pores, which comprise $15 \%$ or more of the total volume of the material. Its inner architecture, including size, shape and communication among pores, have an important role on the in vivo behavior of the biomaterial [75-77]. Therefore, for biomaterials with the same chemical composition, the highest is the porosity, the fastest is the absorption speed for the graft material [70].

A combination of analytical techniques is recommended to address the crystalline properties of calcium phosphate-based biomaterials. Such techniques include X-ray diffraction (XRD), Fourier transform infrared spectroscopy (FT-IR), scan (SEM) and transmission electron microscopy (TEM) and solubility assays [78-81]. Each one of those approaches provide specific data, and present particular limitations, causing the need for their combined use to characterize correctly the material [80].

\subsection{Future Perspective}

Biomaterials are artificial or natural materials that may help on restoring form and function of organs and functional sites and structures. Thus they not only directly help in improving human quality of life but also attend the aging population needs [3].

The future of biosynthetic bone implants still point to autologous bone grafts. There is an increasing interest in combining osteoconductive proteins in osteoconductive carrier media to facilitate timed-release delivery and/or to provide a material scaffold for bone formation. Further, advances in tissue engineering, which integrate the biological, physical and engineering sciences allow the generation of new carriers to repair, regenerate and restore tissue to its functional state. These new products modulate different growth factors, evolving biological scaffolds and incorporation of mesenchymal stem cells. U1timately, the development of ex vivo bioreactors with biomechanical features may provide tissue-engineered constructs for using directly in the skeletal system.

The future of bone graft substitutes continues to be an expanding topic of interest [82]. The current biomaterials are not able to replicate the surface totally and/or the properties of the replaced bone, leading to failure due to insufficient bonding with juxtaposed bone, bone loss, implant loosening and/on fracture.

Nanophase materials possess unique surface and mechanical properties similar to the bone and, hence are considered to be the future generation of orthopedic biomaterials [3]. In fact, lately, the engineering development (i.e. nanotechnology) is greatly increasing biomaterials complexity as well as their biological functions [83]. Biomaterials academic research data such as the analysis of interaction with the host (i.e. binding interactions with cell surface receptors) and applied methodological data such as self-assembly have been used for designing new biomaterials capable of modulating the maintenance and regeneration of specific tissues in the body $[84,85]$.

Currently, to produce new more effective and safer biomaterials, the researchers should consider that biomaterials may modulate specific cell populations distant from the implant site. This can be done either by targeting the material to specific cells or anatomical locations or by controlling the trafficking of target cell populations. Recent reports showed biomaterials as regulators of the immune system and polymeric nano particles designed for non-invasive delivery into the body [86] and for trafficking through the lymphatic vessels to target $\mathrm{T}$ cells in the lymph nodes [87]. Similarly, nanoparticles are being designed to exploit the chemical and physical differences between normal and tumor-associated vasculature to concentrate the particles selectively within or near tumors, allowing subsequent drug-induced cell death [88]. Materials can also be designed to regulate outward migration of transplanted stem cells, or their differentiated progeny to fulfill damaged tissues and promote regeneration efficiently [89].

Clearly the advances in biomaterials will include the development of more functional medical materials and 
the expanded use of biomaterials into new applications. Thus, to mimic important biological processes and/or their functional behavior, it is necessary to fully understand these processes complexity and dynamic, which knowledge is not currently available in most cases. The application of the molecular templating of viruses to optoelectronic device fabrication is an example of this approach $[83,90]$. Biological systems have already inspired the development of cell-programming matrices based on knowledge about infection process, and these matrices accomplish their task with a small subset of key molecular stimuli [91].

The biomaterials research including those with academic and/or industry application purposes is quickly growing and should be redefined. This new definition may include materials that are able to modulate biological processes and those whose design and functions are inspired by natural materials since they may be crucial for improving human quality of life.

\section{Conclusions}

This brief review showed that the biotechnological development initiated in the 50's was accelerated in the last ten years with significant advances for using biomaterials on treating bone remodeling related processes (i.e. orthopedic and odontological treatments). Particularly, calcium phosphates have performed as important biocompatible materials to bone tissue reposition. However together with these innovations, critical risks were identified that can be controlled or avoided by the knowledge about the product features and their interactions with the biological microenvironments.

Based on these data, all future research may focus on addressing both chemical and physical characteristics of biomaterials to better interact with these microenvironments. On that purpose the biological and toxicological profile of each biomaterial must be determined previously to its clinical application to establish its limitation and specificity. Special attention must be given to the principles that rule a new interface, to obtain safer and effective therapeutic treatments.

\section{Acknowledgments}

We thank the Conselho Nacional de Desenvolvimento Científico e Tecnológico (CNPq), Coordenação de Aperfeiçoamento de Pessoal Docente (CAPES-Edital Nanobiotecnologia 2008) and Fundação de Amparo à Pesquisa do Estado do Rio de Janeiro (FAPERJ) for the financial support and fellowships.

\section{REFERENCES}

[1] J. M. Hazes and A. D. Woolf, "The Bone and Joint Dec- ade 2000-2010," The Journal of Rheumatology, Vol. 27, No. 1, 2000, pp. 1-3.

[2] D. Williams, "Definitions in Biomaterials," Proceedings of a Consensus Conference of the European Society for Biomaterials, Chester, 3-5 March 1986, pp. 1-72.

[3] M. Geethaa, A. K. Singhb, R. Asokamania and A. K. Gogiac, "Ti Based Biomaterials, the Ultimate Choice for Orthopaedic Implants-A Review," Progress in Materials Science, Vol. 54, No. 3, 2009, pp. 397-425.

[4] A. Sculean, D. Nikolidakis and F. Schwarz, "Regeneration of Periodontal Tissues: Combinations of Barrier Membranes and Grafting Materials-Biological Foundation and Preclinical Evidence: A Systematic Review," Journal of Clinical Periodontology, Vol. 35, No. 8, 2008, 106-116. doi:10.1111/j.1600-051X.2008.01263.x

[5] Y. Lin, G. O. Gallucci, D. Buser, D. Bosshardt, U. C. Belser and P. C. Yelick, "Bioengineered Periodontal Tissue Formed on Titanium Dental Implants," Journal of Dental Research, Vol. 90, No. 2, 2011, pp. 251-256. doi: $10.1177 / 0022034510384872$

[6] G. Serino, W. Rao, G. Iezzi and A. Piattelli, "Polylactide and Polyglycolide Sponge Used in Human Extraction Sockets: Bone Formation Following 3 Months After Its Application," Clinical Oral Implants Research, Vol. 19, No. 1, 2008, pp. 26-31.

[7] H. Browaeys, P. Bouvry and B. H. De, "A Literature Review on Biomaterials in Sinus Augmentation Procedures," Clinical Implant Dentistry and Related Research, Vol. 9, No. 3, 2007, pp. 166-177. doi:10.1111/j.1708-8208.2007.00050.x

[8] M. Esposito, M. G. Grusovin, P. Coulthard and H. V, Worthington, "The Efficacy of Various Bone Augmentation Procedures for Dental Implants: A Cochrane Systematic Review of Randomized Controlled Clinical trials," The International Journal of Oral \& Maxillofacial Implants, Vol. 21, No. 5, 2006, pp. 696-710.

[9] P. S. Tiwana, G. M. Kushner and R. H. Haug, "Maxillary Sinus Augmentation," Dental Clinics of North America, Vol. 50, No. 3, 2006, pp. 409-24. doi:10.1016/j.cden.2006.03.004

[10] M. A. Reynolds, M. E. Ichelmann-Reidy, G. L. BranchMays and J. C. Gunsolley, "The Efficacy of Bone Replacement Grafts in the Treatment of Periodontal Osseous Defects. A Systematic Review," Annals of Periodontology, Vol. 8, No. 1, 2003, pp. 227-265. doi:10.1902/annals.2003.8.1.227

[11] D. E. Albert, "The Important Role of Material and Chemical Characterisation in Device Evaluation," Medical Device Technology, Vol. 15, No. 5, 2004, pp.15-18.

[12] P. E. Murray, G. C. Garcia and G. F. Garcia, "How is the Biocompatibilty of Dental Biomaterials Evaluated?" Medicina Oral, Patologia Oral y Cirugia Bucal, Vol. 12, No, 3, 2007, pp. E258-E266.

[13] D. Williams, "Revisiting the Definition of Bio-compatibility," Medical Device Technology, Vol. 14, No. 8, 2003, pp. 10-13.

[14] M. B. Nasab and M. R. Hassan, "Metallic Biomaterials of 
Knee and Hip_-A Review," Trends in Biomaterials \& Artificial Organs, Vol. 24, No. 1, 2010, pp. 69-82.

[15] M. Navarro, A. Michiardi, O. Castano and J. A. Planell, "Biomaterials in Orthopaedics," Journal of the Royal Society Interface, Vol. 5, No. 27, 2008, pp. 1137-1158. doi:10.1098/rsif.2008.0151

[16] M. A. Merkx, J. C. Maltha and P. J. Stoelinga, "Assessment of the Value of Anorganic Bone Additives in Sinus Floor Augmentation: A Review of Clinical Reports," International Journal of Oral and Maxillofacial Surgery, Vol. 32, No. 1, 2003, pp.1-6. doi:10.1054/ijom.2002.0346

[17] M. Hallman and A. Thor, "Bone Substitutes and Growth Factors as an Alternative/Complement to Autogenous Bone for Grafting in Implant Dentistry," Periodontology 2000, Vol. 47, No. 1, 2008, pp. 172-192. doi:10.1111/j.1600-0757.2008.00251.x

[18] D. Logeart-Avramoglou, F. Anagnostou, R. Bizios and H. Petite, "Engineering Bone: Challenges and Obstacles," Journal of Cellular and Molecular Medicine, Vol. 9, No. 1,2005 , pp. $72-84$. doi:10.1111/j.1582-4934.2005.tb00338.x

[19] M. Rumpler, A. Woesz, J. W. Dunlop, J. T. Van Dongen and P. Fratzl, "The Effect of Geometry on Three- Dimensional Tissue Growth," Journal of the Royal Society Interface, Vol. 5, No. 27, 2008, pp. 1173-1180. doi:10.1098/rsif.2008.0064

[20] F. Forriol and F. Shapiro, "Bone Development: Interaction of Molecular Components and Biophysical Forces," Clinical Orthopaedics and Related Research, Vol. 432, 2005, pp.14-33.

[21] F. Shapiro, "Bone Development and Its Relation to Fracture Repair. The Role of Mesenchymal Osteoblasts and Surface Osteoblasts," European Cells \& Materials, Vol. 15, 2008, pp. 53-76.

[22] I. Fernández-Tresguerres-Hernández-Gil, M. A. OberaGracia, M. Del-Canto-Pingarron and L. Blanco-Jerez, "Physiological Bases of Bone Regeneration I. Histology and Physiology of Bone Tissue," Medicina Oral, Patologia Oral y Cirugia Bucal, Vol. 11, No. 1, 2006, pp. E47E51.

[23] R. Murugan and S. Ramakrishna, "Development of Nanocomposites for Bone Grafting," Composites Science and Technology, Vol. 65, No. 15-16, 2005, pp. 2385-2406. doi:10.1016/j.compscitech.2005.07.022

[24] K. A. Hing, "Bone Repair in the Twenty-First Century: Biology, Chemistry or Engineering?" Philosophical Transactions. Series A, Mathematical, Physical, and Engineering Sciences, Vol. 362, No. 1825, 2004, pp. 28212850.

[25] G. A. Rodan and T. J. Martin, "Therapeutic Approaches to Bone Diseases," Science, Vol. 289, No, 5484, 2000, pp. 1508-1514. doi:10.1126/science.289.5484.1508

[26] J. Street, M. Bao, L. de Guzman, S. Bunting, J. F. V. Peale, N. Ferrara, H. Steinmetz, J. Hoeffel, J. L. Cleland, A. Daugherty, N. van Bruggen, H. P. Redmond, R. A. Carano and E. H. Filvaroff, "Vascular Endothelial Growth Factor
Stimulates Bone Repair by Promoting Angiogenesis and Bone Turnover," Proceedings of the National Academy of Sciences of the USA, Vol. 99, No. 15, 2002, pp. 96569661. doi:10.1073/pnas.152324099

[27] E. Neovius and T. Engstrand, "Craniofacial Reconstruction with Bone and Biomaterials: Review over the Last 11 Years," Journal of Plastic, Reconstructive \& Aesthetic Surgery, Vol. 63, No. 10, 2010, pp. 1615-23.

[28] B. Baroli, "From Natural Bone Grafts to Tissue Engineering Therapeutics: Brainstorming on Pharmaceutical Formulative Requirements and Challenges," Journal of Pharmaceutical Sciences, Vol. 98, No. 4, 2009, pp. 13171375. doi:10.1002/jps. 21528

[29] T. Martin, J. H. Gooi and N. A. Sims, "Molecular Mechanisms in Coupling of Bone Formation to Resorption," Critical Reviews in Eukaryotic Gene Expression, Vol. 19, No. 1, 2009, pp. 73-88.

[30] B. Clarke, "Normal Bone Anatomy and Physiology," Clinical Journal of the American Society of Nephrology, Vol. 3, Supplement 3, 2008, pp. S131-S139.

[31] M. Degidi, L. Artese, C. Rubini, V. Perrotti, G. Iezzi and A. Piattelli, "Microvessel Density and Vascular Endothelial Growth Factor Expression in Sinus Augmentation Using Bio-Oss," Oral Diseases, Vol. 12, No. 5, 2006, pp. 469-475. doi:10.1111/j.1601-0825.2006.01222.x

[32] L. J. Raggatt and N. C. Partridge, "Cellular and Molecular Mechanisms of Bone Remodeling," The Journal of Biological Chemistry, Vol. 285, No. 33, 2010, pp. 2510325108. doi:10.1074/jbc.R109.041087

[33] K. S. Jones, "Effects of Biomaterial-Induced Inflammation on Fibrosis and Rejection," Seminars in Immunology, Vol. 20, No. 2, 2008, pp. 130-136. doi:10.1016/j.smim.2007.11.005

[34] D. F. Larosa, A. H. Rahman and L. A. Turka, "The Innate Immune System in Allograft Rejection and Tolerance," Journal of Immunology, Vol. 178, No. 12, 2007, pp. 75037509.

[35] A. Shekaran and A. J. García, "Extracellular Matrix-Mimetic Adhesive Biomaterials for Bone Repair," Journal of Biomedical Materials Research. Part A, Vol. 96, No. 1, 2011, pp. 261-272. doi:10.1002/jbm.a.32979

[36] R. C. de Oliveira, E. Carneiro, T. M. Cestari, R. Taga and J. M. Granjeiro, "Dynamics of Subcutaneous Tissue Response to the Implantation of Tetracycline-Treated or Untreated Membrane of Demineralized Bovine Cortical Bone in Rats," Journal of Biomaterials Applications, Vol. 21, No. 2, 2006, pp. 167-178. doi: $10.1177 / 0885328206059798$

[37] R. C. de Oliveira, R. Menezes, T. M. Cestari, E. M. Taga, R. Taga, M. A. Buzalaf and J. M. Granjeiro, "Tissue response to a Membrane of Demineralized Bovine Cortical Bone Implanted in the Subcutaneous Tissue of Rats," Brazilian Dental Journal, Vol. 15, No, 1, 2004, pp. 3-8.

[38] K. El Helow and S. El Askary Ael, "Regenerative Barriers in Immediate Implant Placement: A Literature Review," Implant Dentistry, Vol. 17, No, 3, 2008, pp. 360-371. doi:10.1097/ID.0b013e3181813406 
[39] M. V. Thomas and D. A. Puleo, "Infection, Inflammation, and Bone Regeneration: A Paradoxical Relationship," Journal of Dental Research, 2011, In Press. doi:10.1177/0022034510393967

[40] A. Blinc, M. Bozic, R. Vengust and M. Stegnar, "MethylMethacrylate Bone Cement Surface Does Not Promote Platelet Aggregation or Plasma Coagulation in Vitro," Thrombosis Research, Vol. 114, No. 3, 2004, pp. 179-184. doi:10.1016/i.thromres.2004.05.010

[41] M. T. Clarke, J. S. Green, W. M. Harper and P. J. Gregg, "Cement as a Risk Factor for Deep-Vein Thrombosis. Comparison of Cemented TKR, Uncemented TKR and Cemented THR," Journal of Bone and Joint Surgery (British Volume), Vol. 80, No. 4, 1998, pp. 611-613. doi:10.1302/0301-620X.80B4.8612

[42] A. J. Donaldson, H. E. Thomson, N. J. Harper and N. W. Kenny, "Bone Cement Implantation Syndrome," British Journal of Anaesthesia, Vol. 102, No. 1, 2009, pp. 12-22. doi:10.1093/bja/aen328

[43] H. Aita, N. Tsukimura, M. Yamada, N. Hori, K. Kubo, N. Sato, H. Maeda, K. Kimoto and T. Ogawa, "N-Acetyl Cysteine Prevents Polymethyl Methacrylate Bone Cement Extract-Induced Cell Death and Functional Suppression of Rat Primary Osteoblasts," Journal of Biomedical Materials Research Part A, Vol. 92, No 1, 2010, pp. 285-296. doi:10.1002/jbm.a.32336

[44] P. H. Nilsson, A. E. Engberg, J. Bäck, L. Faxälv, T. L. Lindahl, B. Nilsson and K. N. Ekdahl, "The Creation of an Antithrombotic Surface by Apyrase Immobilization," Biomaterials, Vol. 31, No. 16, 2010, pp. 4484-4491. doi:10.1016/j.biomaterials.2010.02.036

[45] A. P. McGuigan and M. V. Sefton, "The Influence of Biomaterials on Endothelial Cell Thrombogenicity," Biomaterials, Vol. 28, No. 16, 2007, pp. 2547-2571. doi:10.1016/j.biomaterials.2007.01.039

[46] Y. X. Wang, J. L. Robertson, W. B. J. Spillman and R. O. Claus, "Effects of the Chemical Structure and the Surface Properties of Polymeric Biomaterials on Their Biocompatibility," Pharmaceutical Research, Vol. 21, No. 8, 2004, 1362-1373.

doi:10.1023/B:PHAM.0000036909.41843.18

[47] B. F. Lai, A. L. Creagh, J. Janzen, C. A. Haynes, D. E. Brooks and J. N. Kizhakkedathu, "The Induction of Thrombus Generation on Nanostructured Neutral Polymer Brush Surfaces," Biomaterials, Vol. 31, No. 26, 2010, pp. 6710-6718. doi:10.1016/j.biomaterials.2010.05.052

[48] J. Hong, E. K. Nilsson, H. Reynolds, R. Larsson and B. Nilsson, "A New in vitro Model to Study Interaction between Whole Blood and Biomaterials. Studies of Platelet and Coagulation Activation and the Effect of Aspirin," Biomaterials, Vol. 20, No. 7, 1999, pp. 603-11. doi:10.1016/S0142-9612(98)00210-5

[49] D. Ricklin, G. Hajishengallis, K. Yang and J. D. Lambris, "Complement: A Key System for Immune Surveillance and Homeostasis," Nature Immunology, Vol. 11, No. 9, 2010, pp. 785-797. doi:10.1038/ni.1923

[50] E. Cenni, D. Granchi, M. Vancini and A. Pizzoferrato,
"Platelet Release of Transforming Growth Factor-Beta and Beta-Thromboglobulin after in vitro Contact with Acrylic Bone Cements," Biomaterials, Vol. 23, No. 6, 2002, pp. 1479-1484. doi:10.1016/S0142-9612(01)00273-3

[51] E. A. Vogler and C. A. Siedlecki, "Contact Activation of Blood-Plasma Coagulation," Biomaterials, Vol. 30, No. 10, 2009, pp. 1857-1869. doi:10.1016/j.biomaterials.2008.12.041

[52] D. M. Smith, G. M. Cooper, M. P. Mooney, K. G. Marra and J. E. Losee, "Bone Morphogenetic Protein 2 Therapy for Craniofacial Surgery," The Journal of Craniofacial Surgery, Vol. 19, No. 5, 2008, pp. 1244-1259. doi:10.1097/SCS.0b013e3181843312

[53] M. O. Klein, P. W. Kämmerer, T. Scholz, M. Moergel, C. M. Kirchmaier and B. Al-Nawas, "Modulation of Platelet Activation and Initial Cytokine Release by Alloplastic Bone Substitute Materials," Clinical Oral Implants Research, Vol. 21, No. 3, 2010, pp. 336-345. doi:10.1111/j.1600-0501.2009.01830.x

[54] C. T. J. Vangsness, I. A. Garcia, C. R. Mills, M. A. Kainer, M. R. Roberts and T. M. Moore, "Allograft Transplantation in the Knee: Tissue Regulation, Procurement, Processing, and Sterilization," The American Journal of Sports Medicine, Vol. 31, No. 3, 2003, pp. 474-481.

[55] L. K. Cannada, "Viable Bone and Circulatory Factors Required for Survival of Bone Grafts," The Orthopedic Clinics of North America, Vol. 41, No. 1, 2010, pp. 5-13. doi:10.1016/j.ocl.2009.07.008

[56] C. N. Cornell and J. M. Lane, "Current Understanding of Osteoconduction in Bone Regeneration," Clinical Orthopaedics and Related Research, Vol. 355, 1998, pp. S267-S273. doi:10.1097/00003086-199810001-00027

[57] R. Z. LeGeros, "Properties of Osteoconductive Biomaterials: Calcium Phosphates," Clinical Orthopaedics and Related Research, Vol. 395, 2002, pp. 81-98.

[58] M. L. Taga, J. M. Granjeiro, T. M. Cestari and R. Taga, "Healing of Critical-Size Cranial Defects in Guinea Pigs Using a Bovine Bone-Derived Resorbable Membrane," The International Journal of Oral \& Maxillofacial Implants, Vol. 23, No. 3, 2008, pp. 427-36.

[59] M. Retzepi and N. Donos, "Guided Bone Regeneration: Biological Principle and Therapeutic Applications," Clinical Oral Implants Research, Vol. 21, No. 6, 2010, pp. 567-576. doi:10.1111/j.1600-0501.2010.01922.x

[60] R. V. Shevchenko, S. L. James and S. E. James, "A Review of Tissue-Engineered Skin Bioconstructs Available for Skin Reconstruction," Journal of the Royal Society Interface, Vol. 7, No. 43, 2010, pp. 229-258. doi:10.1098/rsif.2009.0403

[61] H. Chim and A. K. Gosain, "Biomaterials in Craniofacial Surgery: Experimental Studies and Clinical Application," Journal of Craniofacial Surgery, Vol. 20, No. 1, 2009, pp. 29-33. doi:10.1097/SCS.0b013e318190dd9e

[62] E. Puricelli, A. Corsetti, D. Ponzoni, G. L. Martins, M. G. Leite and L. A. Santos, "Characterization of Bone Repair In Rat Femur after Treatment with Calcium Phosphate 
Cement and Autogenous Bone Graft," Head \& Face Medicine, Vol. 6, 2010, p.10. doi:10.1186/1746-160X-6-10

[63] D. C. Olsson, N. L. Pippi, G. K. Tognoli and A. G. Raiser, "Bone Marrow Progenitor Cells Enriched Scaffold Biological Behavior in Bone Repair," Ciência Rural, Vol. 38, No. 8, 2008, pp. 2403-2412. doi:10.1590/S0103-84782008000800051

[64] D. W. Lee, K. T. Koo, Y. J. Seol, Y. M. Lee, Y. Ku, I. C. Rhyu, C. P. Chung and T. I. Kim, "Bone Regeneration Effects of Human Allogenous Bone Substitutes: A Preliminary Study," Journal of Periodontal \& Implant Science, Vol. 40. No. 3, 2010, pp. 132-138.

[65] T. J. Blokhuis and T. Lindner, "Allograft and Bone Morphogenetic Proteins: An Overview," Injury, Vol. 39, Suppl. 2, 2008, pp. S33-S36.

[66] K. Kaveh, R. Ibrahim, M. Z. A. Bakar and T. A. Ibrahim, "Bone Grafting and Bone Graft Substitutes," Journal of Animal and Veterinary Advances, Vol. 9, No. 6, 2010, pp.1055-1067. doi:10.3923/javaa.2010.1055.1067

[67] L. V. Marins, T. M. Cestari, A. D. Sottovia, J. M. Granjeiro and R. Taga, "Radiographic and Histological Study of Perennial Bone Deffect Repair in Rat Calvaria after Treatment with Blocks of Porous Bovine Organic Graft Material," Journal of Applied Oral Science, Vol. 12, No. 1, 2004, pp. 62-69. doi:10.1590/S1678-77572004000100012

[68] R. T. Kao, S. Murakami and O. R. Beirne, "The Use of Biologic Mediators and Tissue Engineering in Dentistry," Periodontology 2000, Vol. 50, 2009, pp. 127-153. doi:10.1111/j.1600-0757.2008.00287.x

[69] M. T. Fulmer, I. C. Ison, C. R. Hankermayer, B. R. Constantz, J. Ross, "Measurements of the Solubilities and Dissolution Rates of Several Hydroxyapatites," Biomaterials, Vol. 23, No. 3, 2002, pp.751-755. doi:10.1016/S0142-9612(01)00180-6

[70] V. Karageorgiou and D. Kaplan, "Porosity of 3D Biomaterial Scaffolds and Osteogenesis," Biomaterials, Vol. 26, No. 27, 2005, pp. 5474-5491. doi:10.1016/j.biomaterials.2005.02.002

[71] Z. Artzi, M. Weinreb, N. Givol, M. D. Rohrer, C. E. Nemcovsky, H. S. Prasad and H. Tal, "Biomaterial Resorption Rate and Healing Site Morphology of Inorganic Bovine Bone and Beta-Tricalcium Phosphate in the Canine: A 24-Month Longitudinal Histologic Study and Morphometric Analysis," The International Journal of Oral \& Maxillofacial Implants, Vol. 19, No. 3, 2004, pp. 357-368.

[72] Y. Yang, D. Dennison and J. L. Ong, "Protein Adsorption and Osteoblast Precursor Cell Attachment to Hydroxyapatite of Different Crystallinities," The International Journal of Oral \& Maxillofacial Implants, Vol. 20, No. 2, 2005, pp. 187-192.

[73] G. Bezzi, G. Celotti, E. Landi, T. M. G. La Torretta, I. Sopyan and A. Tampieri, "A Novel Sol-Gel Technique for Hydroxyapatite Preparation," Materials Chemistry and Physics, Vol. 78, No. 3, 2003, pp. 816-824.

\section{doi:10.1016/S0254-0584(02)00392-9}

[74] S. Sharma, V. Sikri, K. M. Sharma and V. M. Sharma, "Regeneration of Tooth Pulp and Dentin: Trends and Advances," Annals of Neurosciences, Vol. 17, No. 1, 2010, pp. 31-43.

[75] T. M. Chu, D. G. Orton, S. J. Hollister, S. E. Feinberg and J. W. Halloran, "Mechanical and in Vivo Performance of Hydroxyapatite Implants with Controlled Architectures," Biomaterials, Vol. 23, No. 5, 2002, pp. 1283-1293. doi:10.1016/S0142-9612(01)00243-5

[76] M. Mastrogiacomo, S. Scaglione, R. Martinetti, L. Dolcini, F. Beltrame, R. Cancedda and R. Quarto, "Role of Scaffold Internal Structure on in Vivo Bone Formation in Macroporous Calcium Phosphate Bioceramics," Biomaterials, Vol. 27, No. 17, 2006, pp. 3230-3237. doi:10.1016/i.biomaterials.2006.01.031

[77] H. Schliephake, R. Gruber, M. Dard, R. Wenz, and S. Scholz, "Repair of Calvarial Defects in Rats by prefabricated Hydroxyapatite Cement Implant," Journal of Biomedical Materials Research Part A, Vol. 69, No. 3, 2004, pp. 382-390. doi:10.1002/jbm.a.20121

[78] T. Accorsi-Mendonca, M. B. Conz, T. C. Barros, L. A. de Sena, G. A. Soares and J. M. Granjeiro, "Physicochemical Characterization of Two Deproteinized Bovine Xenografts," Brazilian Oral Research, Vol. 22, No. 1, 2008, pp. 5-10. doi:10.1590/S1806-83242008000100002

[79] M. D. Calasans-Maia, S. R. A. Santos, A. M. Rossi and J. M. Granjeiro, "In vivo Behavior of Hydroxyapatite Evaluated by Attenuated Total Reflection Infrared Microscopy (ATR-FTIR)," Key Engineering Materials, Vol. 396-398, 2009, pp. 61-64. doi:10.4028/www.scientific.net/KEM.396-398.61

[80] M. B. Conz, J. M. Granjeiro and G. A. Soares, "Physicochemical Characterization of Six Commercial Hydroxyapatites for Medical-Dental Applicatons as Bone Graft," Journal of Applied Oral Science, Vol. 13, No. 2, 2005, pp. 136-140. doi:10.1590/S1678-77572005000200008

[81] K. B. S. Paiva, T. Accorsi-Mendonca, J. M. Granjeiro, R. Taga and C. M. Bramante, "Physicochemical Characterization and Histologic Analysis of Different Xenografts in the Repair of Critical Size Defect in Calvaria of Rats," Bone, Vol. 36, 2005, pp. S186-S187.

[82] S. K. Nandi, S. Roy, P. Mukherjee, B. Kundu, D. K. De and D. Basu, "Orthopaedic Applications of Bone Graft \& Graft Substitutes: A Review," Indian Journal of Medical Research, Vol. 132, 2010, pp. 15-30.

[83] N. Huebsch and D. J. Mooney, "Inspiration and Application in the Evolution of Biomaterials," Nature, Vol. 462, No. 7272, 2009, pp. 426-432. doi:10.1038/nature 08601

[84] H. Shin, K. Zygourakis, M. C. Farach-Carson, M. J. Yaszemski and A. G. Mikos, "Attachment, Proliferation, and Migration of Marrow Stromal Osteoblasts Cultured on Biomimetic Hydrogels Modified with an osteopontin-Derived Peptide," Biomaterials, Vol. 25, No. 5, 2004, pp. 895-906. doi:10.1016/S0142-9612(03)00602-1

[85] S. I. Stupp, "Self-Assembly and Biomaterials," Nano Le- 
tters, Vol. 10, 2010, pp. 4783-4786. doi: $10.1021 / \mathrm{nl} 103567 \mathrm{y}$

[86] N. Tsapis, D. Bennett, B. Jackson, D. A. Weitz and D. A. Edwards, "Trojan Particles: Large Porous Carriers of Nanoparticles for Drug Delivery," Proceedings of the National Academy of Sciences of the USA, Vol. 99, No. 19, 2002, pp. 12001-12005. doi:10.1073/pnas.182233999

[87] S. T. Reddy, A. J. van der Vlies, E. Simeoni, V. Angeli, G. J. Randolph, C. P. O’Neil, L. K. Lee, M. A. Swartz and J. A. Hubbell, "Exploiting Lymphatic Transport and Complement Activation in Nanoparticle Vaccines," $\mathrm{Na}$ ture Biotechnology, Vol. 25, No. 10, 2007, pp. 1159-1164. doi:10.1038/nbt1332

[88] J. H. Park, G. von Maltzahn, L. Zhang, A. M. Derfus, D. Simberg, T. J. Harris, E. Ruoslahti, S. N. Bhatia and M. J. Sailor, "Systematic Surface Engineering of Magnetic Nanoworms for in Vivo Tumor Targeting," Small, Vol. 5, No. 6, 2009, pp. 694-700. doi:10.1002/smll.200801789
[89] E. A. Silva, E. S. Kim, H. J. Kong and D. J. Mooney, "Material-Based Deployment Enhances the Efficacy of Endothelial Progenitor Cells," Proceedings of the $\mathrm{Na}$ tional Academy of Sciences of the USA, Vol. 105, No. 38, 2008, pp. 14347-14352. doi:10.1073/pnas.0803873105

[90] D. J. Needleman, M. A. Ojeda-Lopez, U. Raviv, H. P. Miller, L. Wilson and C. R. Safinya, "Higher-Order Assembly of Microtubules by Counterions: From Hexagonal Bundles to Living Necklaces," Proceedings of the $\mathrm{Na}$ tional Academy of Sciences of the USA, Vol. 101, No. 46, 2004, pp. 16099-16103. doi:10.1073/pnas.0406076101

[91] J. L. Tan, J. Tien, D. M. Pirone, D. S. Gray, K. Bhadriraju and C. S. Chen, "Cells Lying on a Bed of Microneedles: An Approach to Isolate Mechanical Force," Proceedings of the National Academy of Sciences of the USA, Vol. 100, No, 4, 2003, pp. 1484-1489.

doi: $10.1073 /$ pnas. 0235407100 